\title{
PENGARUH VARIASI NILAI RASIO KARBON DAN NITROGEN (C/N RATIO) PADA CAMPURAN KOTORAN KERBAU-SAPI PADA PRODUKSI BIOGAS MENGGUNAKAN SISTEM FERMENTASI BATCH
}

\author{
Purwinda Iriani, Tina Mulya Gantina, Arif Santya Budi dan Florida \\ Jurusan Teknik Konversi Energi - Politeknik Negeri Bandung \\ Email:
}

\begin{abstract}
Abstrak
Penggunaan energi terbarukan di Indonesia mulai mengalami kenaikan, dimana salah satu jenisnya adalah biogas. Penggunaan biogas pada saat ini banyak memanfaatkan kotoran hewan ruminan sebagai bahan baku utama. Pada penelitian ini dilakukan kajian mengenai perbandingan antara produksi biogas berbahan baku campuran kotoran kerbau-sapi dengan $\mathrm{C} / \mathrm{N}$ rasio 40/1, 50/1, 55/1 dan 65/1. Pengujian kimiawi bahan baku penelitian menunjukkan bahwa $\mathrm{C} / \mathrm{N}$ rasio kotoran kerbau adalah $88 / 1$ dan kotoran sapi adalah 38,5/1. Fermentasi bahan baku dilakukan dalam keadaan anaerob pada digester $19 \mathrm{~L}$ di temperatur lingkungan selama 34 hari. Hasil penelitian menunjukkan bahwa total volume biogas tertinggi diperoleh pada bahan baku kerbau-sapi dengan $\mathrm{C} / \mathrm{N}$ rasio $50 / 1$ sebanyak $24.3 \mathrm{~L}$, sedangkan komposisi gas $\mathrm{CH} 4$ tertinggi diperoleh pada baku kotoran kerbau-sapi dengan $\mathrm{C} / \mathrm{N}$ rasio $55 / 1$ yaitu $51,26 \%$ di fermentasi pada hari ke- 15 .
\end{abstract}

The usage of renewable energy has been raising in Indonesia, which is biogas include in the term of it. Nowadays, biogas utilization is generally made by using ruminant's manure as its raw material. This research were conducted by using buffalo's-cow's manure mixture (with 40/1, 50/1, 55/1 and 65/1 of Carbon-Nitrogen-ratio) as the biogas production raw material. The C/N ratio analysis of buffalo's manure shows $88 / 1$ whilst that of the cow's manure is $38,5 \%$. The raw materials fermentation was undergo in a 19-Litre digester, with anaerobic condition and in ambient temperature within 34 days. The result showed that the highest of total biogas volume was reached by $50 / 1$ of C/N ratio buffalo-cow's manure, which is $24.3 \mathrm{~L}$. However, the highest $\mathrm{CH}_{4}$ composition was attempted by $55 / 1$ of $\mathrm{C} / \mathrm{N}$ ratio buffalo-cow's manure, which is $51,26 \%$ of $\mathrm{CH}_{4}$ at $15^{\text {th }}$ day of fermentation.

\section{PENDAHULUAN}

Energi merupakan kebutuhan yang sangat penting, dimana semua aktivitas manusia bergantung pada keberadaan energi. Populasi dan kebutuhan hidup yang semakin meningkat menyebabkan kebutuhan energi seperti listrik dan bahan bakar mesin turut mengalami kenaikan. Akibat dari keadaan tersebut adalah harga sumber energi (minyak bumi) yang semakin merangkak. Untuk mengatasi masalah tersebut diperlukan energi alternatif, dan salah satu energi alternatif yang dapat diaplikasikan di masyarakat (khususnya pedesaan) adalah biogas.

Biogas merupakan gas yang mudah terbakar dan umumnya dihasilkan dari proses fermentasi bahan organik oleh bakteri penghasil metan dalam kondisi anaerob. Nilai kalor $1 \mathrm{~m}^{3}$ biogas (kandungan metan sebesar 75\%) setara dengan 0,6-0,8 Liter minyak tanah (Wahyuni, 2006).

Hanjie (2010) menyebutkan bahwa proses pembentukan biogas meliputi empat tahapan yaitu : (a) Hidrolisis, pada tahap ini terjadi penguraian bahan-bahan organik mudah larut dan pencernaan bahan organik yang komplek menjadi sederhana, perubahan struktur bentuk polimer menjadi bentuk monomer; (b) Acidogenesis, pada tahap pengasaman komponen monomer (gula sederhana) yang terbentuk pada tahap hidrolisis akan menjadi bahan makanan bagi bakteri pembentuk asam. Produk akhir dari perombakan gula-gula sederhana ini yaitu asam propionat, format, laktat, alkohol, dan sedikit butirat, gas karbondioksida, hidrogen dan amonia ; (c) Acidogenesis, pada tahap ini asam asetat terbentuk dari hasil penggunaan senyawa hasil acidogenesis oleh mikroorganisme. Beberapa jenis gas turut dihasilkan, yakni hidrogen dan karbondioksida, (d) Metanogenik, pada tahap metanogenik terjadi proses pembentukan gas metana. Bakteri pereduksi sulfat juga terdapat dalam proses ini, yaitu mereduksi sulfat dan komponen sulfur lainnya menjadi hidrogen sulfida. 
Gas yang dihasilkan sebagian besar merupakan metana, dengan komposisi $55 \%$ hingga $60 \%$, karbondioksida $35-40 \%$, Nitrogen dan Hidrogen Sulfid masing-masing 0-2\% (Suyog,2010). Salah satu bahan organik yang dapat digunakan adalah kotoran kerbau dan sapi yang mudah diperoleh di pedesaan

\section{METODOLOGI PENELITIAN}

Pada penelitian ini digunakan digester tipe batch dengan kapasitas 5 Liter untuk masing-masing campuran bahan pembuatan biogas. Pembuatan digester dan penelitian dilakukan di laboratorium Teknik Konversi Energi.

\section{Alat dan Bahan}

Bahan yang digunakan untuk membuat. Bahan yang digunakan dalam produksi biogas adalah kotoran sapi yang berasal dari sebuah peternakan sapi Cikole-Lembang dan kotoran kerbau diambil dari pertanian di daerah Batujajar, Padalarang.

Alat-alat yang digunakan terdiri dari digester berkapasitas 5 Liter adalah galon air mineral kapasitas $5 \mathrm{~L}$, seal tape, pentil ban, selang karet, selang silikon, ban dalam sepeda, klem, lem perekat, obeng min, pisau, timbangan, ember pengaduk, termometer, suntikan $1 \mathrm{~mL}$, gelas ukur $1000 \mathrm{~mL}$.

\section{Pembuatan Digester}

Galon air mineral kapasitas 5L terlebih dahulu dibersihkan bagian dalamnya, dan kemudian ditutup dengan penutup galon air mineral yang telah dilubangi menggunakan bor tangan. Pada lubang tersebut dipasangkan sebuah pentil. Permukaan luar dan dalam penutup diberikan isolasi yakni memberikan lem perekat agar tidak terjadi kebocoran. Selang plastik dipasang di pentil keluarannya sepanjang 0,5 meter dan diberi klem pada sambungan pentil dan selang plastik. Ujung dari selang waterpass disambungkan dengan selang silikon untuk kemudian sambungan itu diberi isolasi agar tidak terjadi kebocoran. Ujung dari selang silikon kemudian disambung kembali dengan selang waterpass yang menuju ke penampungan gas (ban dalam) dan klem diberikan pada sambungan tersebut.

\section{Pencampuran Bahan}

Total volume bahan baku yang digunakan adalah $80 \%$ dari volume total digester, dimana $20 \%$ sisanya digunakan untuk ruang yang digunakan untuk gas metan dihasilkan.

\section{Kondisi Lingkungan Fermentasi}

Suhu lingkungan dapat mempengaruhi proses fermentasi dari metanogen yang berdampak langsung pada proses pembentukan biogas, hal ini diakibatkan karena bakteri metanogen sangat senstitif terhadap suhu (John, Fry. 1978). Suhu yang optimal untuk proses pembentukan biogas berkisar antara $(25-35)^{\circ} \mathrm{C}$ (Sri Wahyuni, 2009). Perlakuan terhadap digester harus diperhatikan mengingat keadaan cuaca Indonesia yang selalu berubah dan hampir tidak dapat diprediksi. Oleh karena itu tempat penyimpanan digester akan disimpan pada suatu ruangan khusus dengan dinding sekitar ruangan bening yang bertujuan memberikan efek rumah kaca yang menimbulkan panas pada daerah tersebut.

\section{Pengambilan Data Volume}

Karakteristik bahan baku pembuatan biogas berupa kotoran sapi dan limbah cair tahu diuji di Laboratorium Buangan Padat dan B3, Labtek IX C lantai 4 Fakultas Teknik Sipil dan Lingkungan, Institut Teknologi Bandung.

Pengukuran volume gas sendiri dilakukan setiap 4 hari sekali dengan cara mengalirkan gas yang telah tersimpan pada ban melalui air yang berada pada gelas ukur dengan posisi gelas ukur terbalik. Penurunan volume air di dalam gelas ukur merupakan volume gas yang terukur.

Komposisi gas yang dihasilkan dianalisa dengan menggunakan Gas Chromatograf. Analisa ini dilakukan di Lab. Teknologi X ITB. Gas yang dapat dideteksi oleh alat ini diantaranya $\mathrm{CH}_{4}$ dan $\mathrm{CO}_{2}$.

\section{HASILDAN PEMBAHASAN}

Karakteristik kimiawi masing-masing bahan baku yang diperoleh dari hasil pengujian laboratorium dapat dilihat pada Tabel 1 . Diperoleh bahwa nilai $\mathrm{C} / \mathrm{N}$ rasio kotoran kerbau sebesar 88,81 sedangkan kotoran sapi sebesar 38,54 . Kedua jenis kotoran tersebut dicampur hingga nilai rasio $\mathrm{C} / \mathrm{N}$ masing-masing perlakuan adalah 40/1, 50/1, 55/1, dan 60/1. 
Tabel 1. Karakteristik Kimia Bahan Baku Biogas

\begin{tabular}{ccccc}
\hline No & Parameter & Satuan & \multicolumn{2}{c}{ Hasil Analisa } \\
\cline { 4 - 5 } & & & $\begin{array}{l}\text { Kotoran } \\
\text { Kerbau }\end{array}$ & $\begin{array}{c}\text { Kotoran } \\
\text { Sapi }\end{array}$ \\
\cline { 4 - 5 } $\mathbf{1}$ & Kadar Air & $\% \mathrm{BB}$ & 88 & 84,62 \\
\hline $\mathbf{2}$ & $\mathrm{pH}$ & - & 5,8 & 6,65 \\
\hline $\mathbf{3}$ & $\mathrm{NTK}$ & $\% \mathrm{BK}$ & 0,6 & 1,53 \\
\hline $\mathbf{4}$ & $\mathrm{C}-$ - Organik & $\% \mathrm{BK}$ & 52,8 & 45,66 \\
\hline $\mathbf{5}$ & $\mathrm{C} / \mathrm{N}$ & $\%$ & 88,81 & 38,54 \\
\hline
\end{tabular}

Menurut (Fairus, 2011). bahan baku biogas harus memiliki kandungan air optimum sebesar $90 \%$. Berdasarkan hasil pengujian kadar air kedua sampel kotoran, maka nilai tersebut berada di dalam rentang nilai kadar air bahan baku pembuatan biogas.

Volume biogas yang dihasilkan pada setiap perlakuan memiliki profil yang berbeda-beda (Tabel 2). Aktivitas fermentasi anaerobik telah dapat dilihat pada hari ke-4, dimana masingmasing perlakuan telah menghasilkan biogas, dimana volume biogas pada rasio $\mathrm{C} / \mathrm{N} 40$ dan 50 memiliki nilai dua kali lipat dari rasio $\mathrm{C} / \mathrm{N} 55$ dan 65. Produksi biogas paling tinggi dihasilkan pada perlakuan dengan rasio $\mathrm{C} / \mathrm{N} 50$, yakni $3.3 \mathrm{~L}$ pada hari ke-15. Produksi biogas setelah hari ke15 pada perlakuan rasio $\mathrm{C} / \mathrm{N} 50$ dan 55 relatif stabil dibandingkan perlakuan rasio $\mathrm{C} / \mathrm{N} 40$ dan C/N 65 .

Tabel 2. Produksi Volume Biogas (Liter)

\begin{tabular}{|c|c|c|c|c|}
\hline \multirow{2}{*}{$\begin{array}{c}\text { hari } \\
\text { ke- }\end{array}$} & $\mathrm{C} / \mathrm{N} 40$ & $\mathrm{C} / \mathrm{N} 50$ & $\mathrm{C} / \mathrm{N} 55$ & $\mathrm{C} / \mathrm{N}$ 65 \\
\cline { 2 - 5 } & 0 & 0 & 0 & 0 \\
\hline 4 & 3,05 & 2,9 & 1,4 & 1,5 \\
\hline 8 & 3 & 3 & 3 & 3 \\
\hline 12 & 3,2 & 3,1 & 3,1 & 3 \\
\hline 15 & 3,2 & 3,1 & 3,3 & 2,8 \\
\hline 19 & 3,1 & 3,1 & 3 & 2,8 \\
\hline 21 & 3 & 3,1 & 3 & 2,6 \\
\hline 26 & 2,85 & 3 & 3 & 1,9 \\
\hline 34 & 2,75 & 3 & 3 & 1,6 \\
\hline total & $\mathbf{2 4 , 1 5}$ & $\mathbf{2 4 , 3}$ & $\mathbf{2 2 , 8}$ & $\mathbf{1 9 , 2}$ \\
\hline
\end{tabular}

Akumulasi volume biogas selama fermentasi dapat dilihat pada Gambar 1. Profil peningkatan produksi biogas pada rasio $\mathrm{C} / \mathrm{N} 50$ relatif lebih tinggi dibandingkan perlakuan lainnya, dengan total akumulasi gas yang dihasilkan selama 34 hari fermentasi adalah $24.3 \mathrm{~L}$.

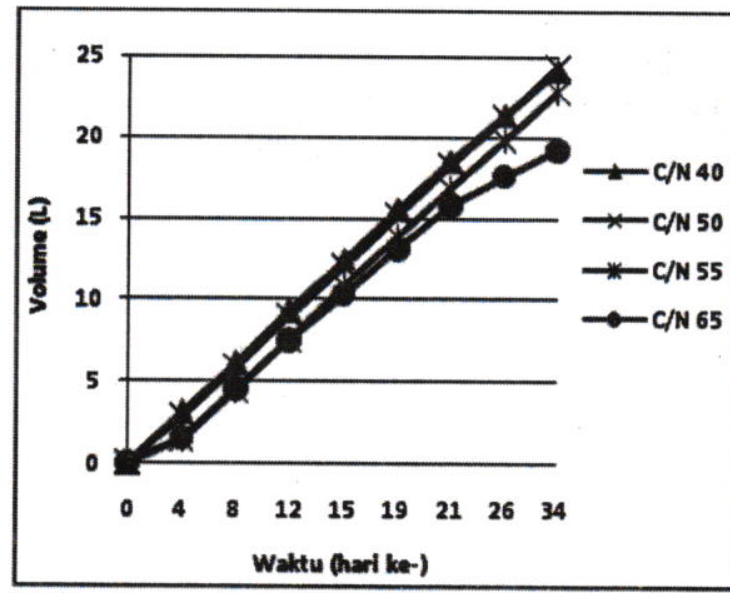

Gambar 1. Grafik Akumulasi Volume Biogas Selama 34 Hari Fermentasi

Perlakuan menggunakan bahan baku rasio $\mathrm{C} / \mathrm{N}$ 65 menunjukkan aktivitas fermentasi anaerobik yang lebih rendah dibandingkan perlakuan lainnya. Hal tersebut dapat terjadi karena nilai rasio $\mathrm{C} / \mathrm{N}$ yang tinggi. Menurut Schnurer dan Jarvis (2010) aktivitas pembentukan biogas dipengaruhi oleh proses hidrolisis bahan baku, dimana semakin tinggi rasio $\mathrm{C} / \mathrm{N}$ maka proses hidrolisis senyawa kompleks akan memakan waktu lebih lama.

Pada penelitian ini, nilai volume biogas yang diproduksi tidak berkolerasi pada nilai kandungan gas metan $\left(\mathrm{CH}_{4}\right)$ yang terdapat di dalam biogas. Hal tersebut dapat dilihat pada Gambar 2.

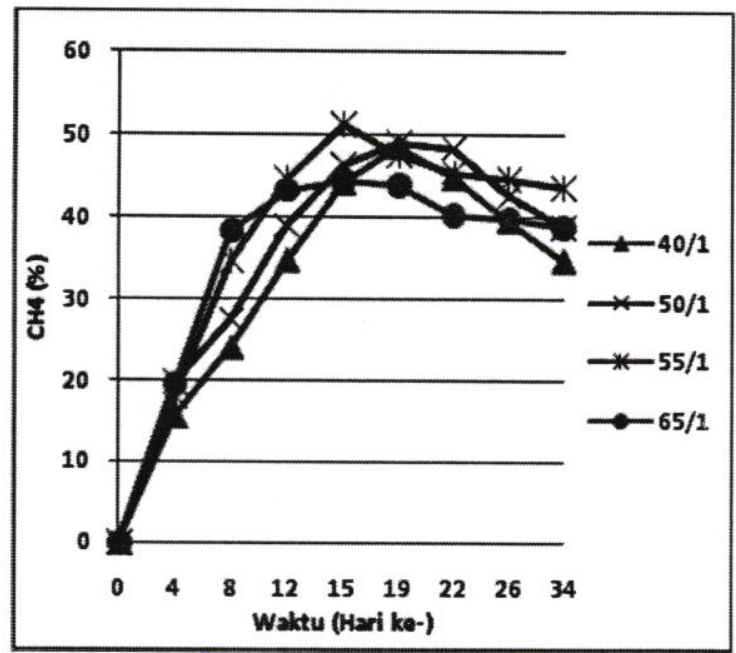

Gambar 2. Grafik Komposisi CH4 pada Biogas

Pada Grafik diatas menunjukkan bahwa gas $\mathrm{CH}_{4}$ telah diproduksi pada hari ke-4 di masing- 
masing perlakuan. Nilai komposisi gas $\mathrm{CH}_{4}$ paling tinggi diperoleh pada perlakuan dengan rasio $\mathrm{C} / \mathrm{N} 55 / 1$ yaitu $51.26 \%$ pada hari ke- 15 . Pada hari yang sama, perlakuan dengan rasio $\mathrm{C} / \mathrm{N} \mathrm{65/1}$ menghasilkan nilai $\% \mathrm{CH}_{4}$ tertinggi selama fermentasi, yaitu $44.52 \%$. Sedangkan nilai $\% \mathrm{CH}_{4}$ tertinggi pada perlakuan dengan rasio $\mathrm{C} / \mathrm{N}$ 40/1 dan 50/1 pada hari ke-19, dengan masing-masing mencapai $48.58 \%$ dan $49.20 \%$.

Profil komponen gas lainnya yang terukur selama proses produksi biogas adalah gas $\mathrm{CO}_{2}$. Pada Grafik 3 menunjukkan bahwa profil persentase gas $\mathrm{CO}_{2}$ selama fermentasi pada perlakuan dengan rasio $\mathrm{C} / \mathrm{N} \mathrm{55/1}$ relatif lebih rendah dibandingkan perlakuan lainnya. Pada saat persentase gas metan tertinggi (hari ke-15), nilai $\%$ gas $\mathrm{CO}_{2}$ pada perlakuan tersebut adalah $32.37 \%$. Pada hari yang sama, persentase $\mathrm{CO}_{2}$ pada perlakuan dengan rasio $\mathrm{C} / \mathrm{N} 40 / 1,50 / 1$, dan $65 / 1$ masing-masing adalah $48.91 \%, 43.91 \%$ dan $43.21 \%$.

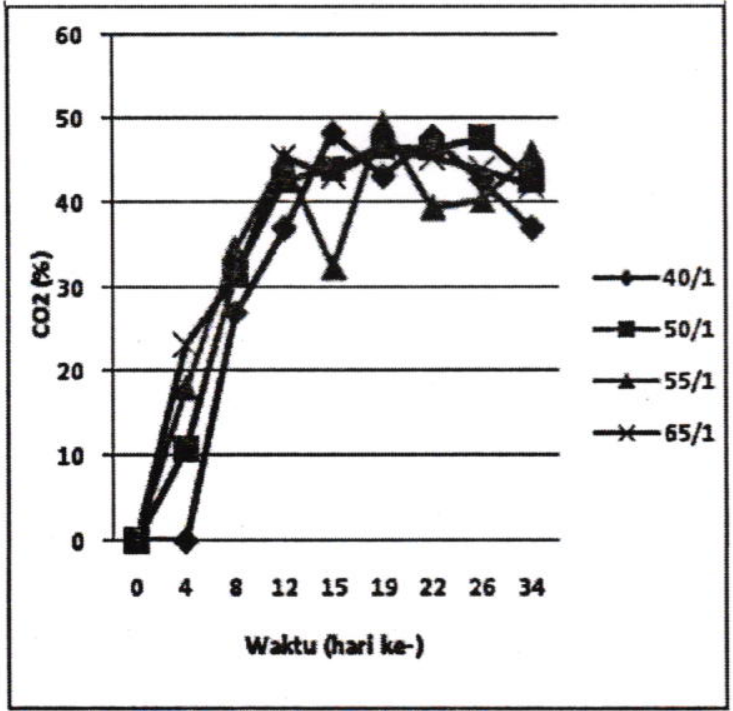

Gambar 3. Grafik Komposisi CO2 pada Biogas

Rasio perbandingan gas $\mathrm{CH}_{4} / \mathrm{CO}_{2}$ dapat dilihat pada Gambar 4. Histogram pada gambar tersebut menunjukkan bahwa rasio $\mathrm{CH} 4 / \mathrm{CO} 2$ paling besar adalah pada perlakuan perlakuan dengan rasio $\mathrm{C} / \mathrm{N} 55 / 1$, yaitu 1.58 . Sedangkan pada perlakuan lainnya hanya pada kisaran 0.92 hingga 1.06. Secara umum, persentase gas metan dan karbondioksida pada produksi biogas dari penggunaan kotoran hewan, masing-masing mendekati 60\% dan 40\% (Bothi, 2007). Berdasarkan hasil pengukuran, maka persentase tertinggi gas $\mathrm{CH} 4$ yang diproduksi pada perlakuan dengan rasio $\mathrm{C} / \mathrm{N}$ $55 / 1$ di hari ke-15 mendekati nilai ideal rasio $\mathrm{CH}_{4} / \mathrm{CO}_{2}$.

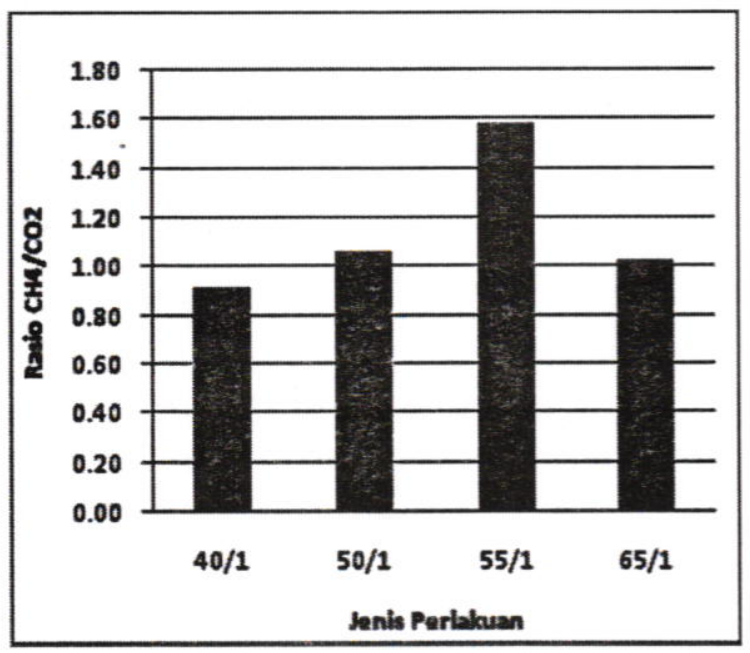

Gambar 4. Perbandingan Rasio $\mathrm{CH}_{4} / \mathrm{CO}_{2}$ pada Setiap Perlakuan pada Fermentasi Hari ke-15

Jumlah volume biogas yang diproduksi dan persentase gas metan yang dihasilkan akan menunjukkan nilai kalor biogas dan potensi energi yang terkandung di dalamnya. Pada Tabel 3 ditunjukkan nilai kalor biogas tertinggi diperoleh pada perlakuan dengan rasio $\mathrm{C} / \mathrm{N} 55 / 1$ di hari ke-15, yaitu $1838.4 \mathrm{~kJ} / \mathrm{L}$. Nilai kalor biogas tersebut berkolerasi dengan persentase komposisi gas metan yang dihasilkan.

Tabel 3. Nilai Kalor Biogas

\begin{tabular}{|c|c|c|c|c|}
\hline \multirow{2}{*}{$\begin{array}{c}\text { hari } \\
\text { ke }\end{array}$} & \multicolumn{5}{|c|}{ Nilai Kalor Biogas (kJ/L) } \\
\cline { 2 - 5 } & C/N 40 & C/N 50 & C/N 55 & C/N 65 \\
\hline 0 & 0 & 0 & 0 & 0 \\
\hline 4 & 560.9 & 712.6 & 645.6 & 701.5 \\
\hline 8 & 864.0 & 988.4 & 1245.6 & 1376.1 \\
\hline 12 & 1246.6 & 1400.5 & 1598.1 & 1556.5 \\
\hline 15 & 1586.3 & 1670.6 & 1838.4 & 1596.7 \\
\hline 19 & 1742.3 & 1764.5 & 1705.7 & 1574.8 \\
\hline 22 & 1607.4 & 1739.8 & 1632.2 & 1449.3 \\
\hline 26 & 1422.0 & 1534.3 & 1601.7 & 1433.9 \\
\hline 34 & 1246.6 & 1395.5 & 1568.0 & 1395.5 \\
\hline
\end{tabular}

Potensi energi yang dihasilkan dari biogas merupakan hubungan antara volume biogas yang dihasilkan dan komposisi metan yang terkandung di dalamnya. Pada Tabel 4 diperoleh hasil perhitungan potensi energibiogas tertinggi adalah $6066.7 \mathrm{~kJ}$ yang 
diperoleh pada perlakuan dengan rasio $\mathrm{C} / \mathrm{N}$ 55/1 dihari ke-15.

Tabel 4. Potensi Energi Biogas Tiap Perlakuan

\begin{tabular}{|c|c|c|c|c|}
\hline hari & \multicolumn{5}{|c|}{ Potensi Energi Biogas (kJ) } \\
\hline $\mathrm{ke}$ & $\mathrm{C} / \mathrm{N} 40$ & $\mathrm{C} / \mathrm{N} 50$ & $\mathrm{C} / \mathrm{N} 55$ & $\mathrm{C} / \mathrm{N} 65$ \\
\hline 0 & 0.0 & 0.0 & 0.0 & 0.0 \\
\hline 4 & 1710.8 & 2066.6 & 903.8 & 1052.3 \\
\hline 8 & 2591.9 & 2965.3 & 3736.7 & 4128.3 \\
\hline 12 & 3989.3 & 4341.6 & 4954.2 & 4669.5 \\
\hline 15 & 5076.1 & 5178.7 & 6066.7 & 4470.7 \\
\hline 19 & 5401.1 & 5470.0 & 5117.1 & 4409.4 \\
\hline 22 & 4822.3 & 5393.3 & 4896.6 & 3768.1 \\
\hline 26 & 4052.8 & 4602.8 & 4805.1 & 2724.3 \\
\hline 34 & 3428.3 & 4186.4 & 4704.0 & 2232.8 \\
\hline Total & 31072.5 & 34204.8 & 35184.1 & 27455.5 \\
\hline
\end{tabular}

Total potensi energi biogas tertinggi yang dihasilkan selama fermentasi adalah 35,184.1 $\mathrm{kJ}$, yang dihasilkan pada perlakuan dengan rasio C/N 55/1 . Sedangkan total potensi energi biogas terendah diperoleh pada perlakuan dengan rasio C/N 65/1, yaitu 27,455.5 kJ.

\section{KESIMPULAN}

1. Total volume produksi biogas tertinggi dihasilkan selama fermentasi adalah pada perlakuan dengan rasio $\mathrm{C} / \mathrm{N} 50$ yaitu adalah $24.3 \mathrm{~L}$.

2. Nilai persentase gas metan tertinggi diperoleh pada diperoleh pada perlakuan dengan rasio $\mathrm{C} / \mathrm{N} 55 / 1$ yaitu $51.26 \%$ pada hari ke-15.

3. Penggunaan campuran bahan baku kotoran kerbau-sapi dengan rasio $\mathrm{C} / \mathrm{N}$ 55/1 lebih baik dibandingkan rasio $\mathrm{C} / \mathrm{N} 40 / 1,50 / 1$, dan $65 / 1$, yakni dengan menghasilkan total nilai potensi energi tertinggi sebesar 35,184.1 kJ.

\section{DAFTAR PUSTAKA}

Bothi, Kimberly Lynn. 2007. Characterization Of Biogas From Anaerobically Digested Dairy Waste For Energy Use. Cornell University. New York, United States OfAmerica

Wahyuni, Sri. 2006. BIOGAS. Penerbit : Penebar Swadaya. Depok.

Suyog, Vij. 2010. Biogas Production From Kitchen Waste Seminar Report,
Department Of Biotechnology And Medical Engineering, NIT Rourkela, Odhisa.

Hanjie, Zhang. 2010 .Sludge Treatment To Increase Biogas Production. TritaLWR Degree Project 10-20. Sweden

Fairus, Sirin Dkk. 2011, Pemanfaatan Sampah Organik Secara Padu, Teknik Kimia, Fakultas Teknologi Industri, Institut Teknologi Nasional, Bandung.

Schnurer, Anna And Asa Jarvis. 2010. Microbiological Handbook For Biogas Plants. Swedish Gas Centre Report 207. Swedia. 